\title{
And later they came to the Primigenio
}

\author{
Jorge Meyrán García* \\ Hospital career history in the Hospital General de México
}

*Corresponding author: Jorge Meyrán García, Hospital career history in the Hospital General de México, Mexico

\section{Opinion}

Georges Lemaitre's first-time atom, or the big bang in English, was the beginning of the universe. From a very small thing began to appear the elements, matter, gases, liquids, like water, then the nebulae, within them the solar systems with their planets, satellites and comets. A small solar system in a corner of a small galaxy called the Milky Way had several planets, some large and other boys; among the little ones one had water where over time surfaces appeared with chlorine arrow that needed the sun's rays to live and develop, then began to form beings that could move, the animals of which there were microscopic and later reached gigantic. Many millennia later Eve and Adam appeared, who were very good animals but one day they came up with sin and they stopped being animals. The animals did not sin, and first time felt naked. If Eve had not sinned today, we would all walk naked, we would be very good little animals and Jesus of Nazareth would not have had to come, because He came for sinners, not for the saints or the virtuous. A good ateor, sincerely, you can say that you do not believe in God, you must believe in the primal atom, which by analyzing its existence can be considered to be God.

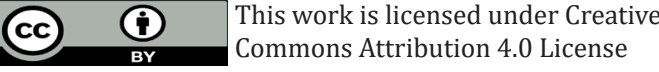

To Submit Your Article Click Here:

Submit Article
DOI: $10.32474 /$ TOOAJ.2020.02.000146 